\title{
Article \\ Comparative Analysis of Biological Activity of Artificial and Wild Agarwood
}

\author{
Sheng Ma, Mengji Qiao, Yunlin Fu, Penglian Wei *, Yingjian Li and Zhigao Liu $\mathbb{C}$ \\ College of Forestry, Guangxi University, Nanning 540004, China; 1909302007@st.gxu.edu.cn (S.M.); \\ 20070034@gxu.edu.cn (M.Q.); fuyunlin@gxu.edu.cn (Y.F.); liyingjian@gxu.edu.cn (Y.L.); lzgk18@gxu.edu.cn (Z.L.) \\ * Correspondence: weipenglian@gxu.edu.cn
}

check for

updates

Citation: Ma, S.; Qiao, M.; Fu, Y.; Wei, P.; Li, Y.; Liu, Z. Comparative Analysis of Biological Activity of Artificial and Wild Agarwood. Forests 2021, 12, 1532. https://doi.org/ 10.3390/f12111532

Received: 7 October 2021

Accepted: 3 November 2021

Published: 7 November 2021

Publisher's Note: MDPI stays neutral with regard to jurisdictional claims in published maps and institutional affiliations.

Copyright: (c) 2021 by the authors. Licensee MDPI, Basel, Switzerland. This article is an open access article distributed under the terms and conditions of the Creative Commons Attribution (CC BY) license (https:/ / creativecommons.org/licenses/by/ $4.0 /)$.

\begin{abstract}
Agarwood is a highly economically important medicinal herb with widespread uses; however, the difference between the biological activities of artificial and wild agarwood is unclear. In this study, the alcohol-soluble extracts of agarwood produced by fungi and natural agarwood were used to determine the differences between the overall biological activities. The antioxidant ability (the clearance rates of 1,1-diphenyl-2-picrylhydrazyl (DPPH) and 2,2'-azino-bis (3-ethylbenzothiazoline6-sulfonic acid) $\left(\mathrm{ABTS}^{+}\right)$radicals, and total reducing power), anti-acetylcholinesterase, and anti- $\alpha$ glucosidase activity were determined by ultraviolet-visible spectrophotometry. The results indicated that with $2 \mathrm{mg} / \mathrm{mL}$ alcohol-soluble extracts, the scavenging DPPH radical rates of the artificial agarwood samples were $93.74-102.31 \%$ of that of the wild agarwood, and the ABTS ${ }^{+}$radical clearance rates of the artificial agarwood samples were $75.38-95.52 \%$ of that of the natural agarwood. With $3.5 \mathrm{mg} / \mathrm{mL}$ alcohol-soluble extracts, the artificial agarwood samples had a total reducing power of $63.07-80.29 \%$ of that of the wild agarwood. With $4 \mathrm{mg} / \mathrm{mL}$ alcohol-soluble extract, the acetylcholinesterase activity inhibition rates of the artificial agarwood samples were $102.56-109.16 \%$ of that of the wild agarwood. With $1 \mathrm{mg} / \mathrm{mL}$ alcohol soluble extracts, the $\alpha$-glucosidase effect inhibitions rates of the artificial agarwood samples were $68.32-100.39 \%$ of that of the wild agarwood.
\end{abstract}

Keywords: artificial agarwood; wild agarwood; antioxidant ability; anti-acetylcholinesterase activity; anti- $\alpha$-glucosidase activity

\section{Introduction}

Agarwood is a medicinal herb produced by Aquilaria of the Thymelaeaceae family. The 21 Aquilaria species are mainly distributed in approximately 20 countries from India to Malaysia to Papua New Guinea [1]. In China, they are mainly distributed in Guangxi, Guangdong, Yunnan and Hainan, among which Aquilaria sinensis and Aquilaria yunnanensis are endemic [2]. According to records, the utilization history of agarwood can be traced back to more than 2000 years ago [3], and its unique components are commonly used in the fields of incense, medicine, and religion [4]. Under natural conditions, it is impossible for a healthy Aquilaria tree to contain agarwood. Only external stress factors, causing a tree to activate a defense response, and the accumulation of secondary metabolic substances lead to the formation of agarwood [5]. Thus, the generation of agarwood is coincidental, and agarwood formation may take decades of processing [6]. Furthermore, over the years, wild agarwood resources have been over-harvested [7], resulting in a scarcity of natural agarwood. To meet the market demand for agarwood, Aquilaria trees have been planted artificially on a large scale in China and Southeast Asian countries. At present, there are more than five hundred million Aquilaria trees [1], and for accelerating the agarwood production in Aquilaria plantations, physical, chemical, and biological methods have been developed to induce agarwood formation [8,9]. Natural agarwood has various biological activities such as antioxidant, hypoglycemic, anti-bacterial, and anti-inflammatory [10,11], making a resource with high potential for application as a natural active ingredient. Thus 
far, 443 components have been identified in agarwood, of which 197 compounds have been isolated [12]. Many of them have been assayed for their biological activities, such as (6S,7S,8S)-6,7,8-trihydroxyl-2-(3-hydroxyl-4-methoxylphenylethyl)-5,6,7,8-tetrahydro$4 \mathrm{H}$-chromen-4-one, 6-hydroxy-2-(2-phenylethyl)chromone, (5S,7S,9S,10S)-(+)-9-hydroxyselina-3,11-dien-12-al acetylcholinesterase inhibitory activity [13-15], and 6,7-dimethoxy2-[2-(4-methoxyphenyl)ethyl]chromone having anti-inflammatory and $\alpha$-glucosidase inhibitory abilities $[16,17]$. The Chinese Pharmacopeia has several requirements for the quality of agarwood [18], however, currently, it does not include biological activity. Moreover, many components of agarwood have not been identified and isolated, and not all isolated components have been measured for their biological activity capacity. There have been few studies on the overall activity capacity of agarwood, and there is little literature describing the difference between the bioactivity levels of artificial and wild agarwood. Therefore, it is difficult to evaluate the bioactivity of artificial agarwood, which is an important aspect to study.

In this study, a new fungal inducer was injected into Aquilaria plants to stimulate the generation of large agarwood content. According to the Chinese Pharmacopeia, the content of the alcohol-soluble extract of agarwood is an important index [18], and sesquiterpenes and chromones are the main active components of this extract. Therefore, we conducted a study on the overall bioactivity of artificial agarwood by extracting its alcohol-soluble extract, and determined the antioxidant capacity (1,1-diphenyl-2-picrylhydrazyl (DPPH) radical scavenging ability, 2,2'-azino-bis (3-ethylbenzothiazoline-6-sulfonic acid) (ABTS ${ }^{+}$) radical clearance ability, and total reducing power), acetylcholinesterase activity inhibition ability, and $\alpha$-glucosidase activity inhibition effect. We also compared the biological activity of the artificial and wild agarwood. The results of this study provide a theoretical basis for the utilization of artificial agarwood in application, such as development of natural antioxidants, Alzheimer's disease delay, and blood sugar-lowering products, which are of great significance for accelerating the industrialization of artificial agarwood.

\section{Materials and Methods}

\subsection{Materials}

Fungal inoculation experiments were conducted on healthy (Figure S1), more than 4 years old and $\geq 5 \mathrm{~cm}$ in diameter $A$. sinensis and A. crassna trees in Beihai and Pingxiang cities, Guangxi, China, at their breast height (Table 1).

Table 1. Sample formation.

\begin{tabular}{cccc}
\hline Sample No. & Species Name & Inoculation Time & Number of Samples \\
\hline C12 & A. crassna & 12 months & $\mathrm{N}=3$ \\
C18 & A. crassna & 18 months & $\mathrm{N}=3$ \\
A6 & A. sinensis & 6 months & $\mathrm{N}=3$ \\
A12 & A. sinensis & 12 months & $\mathrm{N}=3$ \\
A18 & A. sinensis & 18 months & $\mathrm{N}=3$ \\
\hline
\end{tabular}

Whole plants were harvested after 6, 12, and 18 months; samples were collected and dried (Figure 1), and the obtained black resin was agarwood (Figure S2). The control group was black wild agarwood (YS) with a high oil content produced by A. sinensis, and it was purchased from the agarwood market in Hainan province, China. 


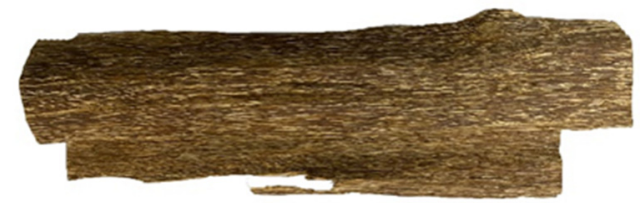

Artificial agarwood

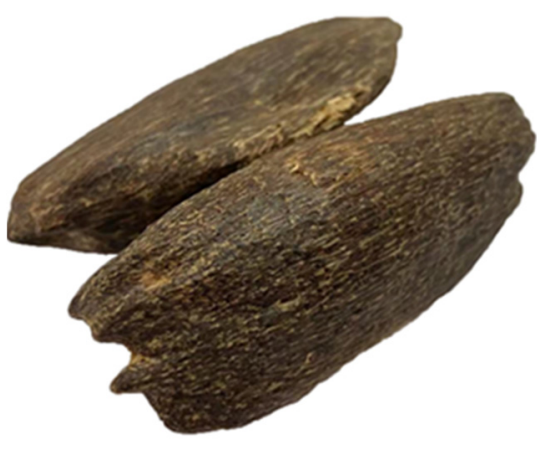

Wild agarwood

Figure 1. Artificial and wild agarwood.

\subsection{Methods}

\subsubsection{Preparation of Alcohol-Soluble Extract}

According to the method of the Chinese Pharmacopeia [18], with modification, batches of agarwood samples were crushed and passed through a 40-mesh sieve. Approximately $10 \mathrm{~g}$ of the sieved powder was taken and $250 \mathrm{~mL}$ of $95 \%$ ethanol was added. The mixture was allowed to stand for $1 \mathrm{~h}$, heated at reflux to boiling, kept at a slight boil for $1 \mathrm{~h}$, and filtered. This process was repeated twice and the filtrates were combined, concentrated under reduced pressure, and dried for $24 \mathrm{~h}$ to obtain the alcohol-soluble extract of agarwood.

\subsubsection{DPPH Free Radical Clearance Capacity}

Referring to the method of Yang et al. [19], each alcohol-soluble extract was dissolved in anhydrous ethanol, and sample solutions with concentrations of $0.2,0.4,0.6,1.0,1.6$, and $2.0 \mathrm{mg} / \mathrm{mL}$ were prepared. Subsequently, to $2.5 \mathrm{~mL}$ of each sample solution, $2.5 \mathrm{~mL}$ of a DPPH solution $(0.2 \mathrm{mM})$ was added and completely mixed, and a dark reaction was conducted for $20 \mathrm{~min}$. The absorbance at $517 \mathrm{~nm}$ was measured by ultraviolet-visible (UVVis) spectrophotometer (GE, Ultrospec 2100 PRO, Amersharm Bioscience, NJ, USA) and was denoted as $A_{1}$. Subsequently, in the above process, the DPPH solution was replaced by ethanol, keeping all other conditions the same, and the corresponding measured absorbance was denoted as $A_{2}$. The sample solution was substituted with ethanol, and all other conditions were consistent with those for obtaining $A_{1}$, and the absorbance was measured. This absorbance was denoted as $\mathrm{A}_{0}$. In accordance with the above conditions, a control test was performed with equal concentrations of ascorbic acid (VC) and wild agarwood.

$$
\text { DPPH Free radical clearance rate }(\%)=\left[1-\left(\frac{\mathrm{A}_{1}-\mathrm{A}_{2}}{\mathrm{~A}_{0}}\right)\right] \times 100 \% \text {. }
$$

\subsection{3. $\mathrm{ABTS}^{+}$Free Radical Clearance Ability}

According to the method of Li et al. [20], with modifications, solutions of 2,2-azinobis (3-ethylbenzothiazoline-6-sulfonic acid) $(7 \mathrm{mM})$ and $\mathrm{K}_{2} \mathrm{~S}_{2} \mathrm{O}_{8}(4.9 \mathrm{mM})$ were mixed in equal proportions, and a dark reaction was conducted for $12 \mathrm{~h}$ to obtain $\mathrm{ABTS}^{+}$radicals. Moreover, ethanol was used to dilute them till an absorbance value of $0.7 \pm 0.02$ was reached. Appropriate amounts of alcohol-soluble extracts were dissolved in anhydrous ethanol and sample solutions of $0.2,0.4,0.6,1.0,1.6$, and $2 \mathrm{mg} / \mathrm{mL}$ concentrations were prepared. Subsequently, $0.5 \mathrm{~mL}$ of a sample solution was added to $3 \mathrm{~mL}$ of the $\mathrm{ABTS}^{+}$ solution, and absorbance $\mathrm{A}_{1}$ was measured at $734 \mathrm{~nm}$ after the dark reaction for $15 \mathrm{~min}$. The $\mathrm{ABTS}^{+}$solution was replaced with ethanol while keeping all other conditions the same as above, and the absorbance was measured, which was denoted as $A_{2}$. The sample solution was replaced with ethanol while keeping all other conditions consistent with those 
for obtaining $A_{1}$, and the absorbance was measured which was denoted as $A_{0}$. A mixture of equal concentrations of wild agarwood and VC solutions was used as a control.

$$
\mathrm{ABTS}^{+} \text {free radical clearance rate }(\%)=\left[1-\left(\frac{\mathrm{A}_{1}-\mathrm{A}_{2}}{\mathrm{~A}_{0}}\right)\right] \times 100 \% .
$$

\subsubsection{Total Reducing Power}

Referring to the method of Berker et al. [21], with some modification, the alcoholsoluble extracts were weighed appropriately and dissolved in anhydrous ethanol to prepare sample solutions with concentrations of $0.6,1.0,1.6,2.0,3.0$, and $3.5 \mathrm{mg} / \mathrm{L}$. Subsequently, $800 \mu \mathrm{L}$ of phosphate working buffer solution (0.2M, pH 6.6), $50 \mu \mathrm{L}$ of a sample solution, and $1 \mathrm{~mL}$ of $\mathrm{K}_{3} \mathrm{Fe}(\mathrm{CN})_{6}$ solution $(1 \%)$ were added to a test tube and heated in a water bath at $50{ }^{\circ} \mathrm{C}$ for $20 \mathrm{~min}$, following which $1 \mathrm{~mL}$ of trichloroacetic acid solution $(10 \%)$ was added and thoroughly mixed. Finally, $1 \mathrm{~mL}$ of the solution was removed, and $1 \mathrm{~mL}$ of water and $200 \mu \mathrm{L}$ of $\mathrm{FeCl}_{3}$ solution $(0.1 \%)$ were sequentially added to the removed solution. Absorbance $\mathrm{A}_{1}$ was determined at $700 \mathrm{~nm}$ after $10 \mathrm{~min}$. The sample solution was replaced with ethanol while keeping all other steps consistent with the above process, and the absorbance was measured, which was denoted as $\mathrm{A}_{0}$.

Total reducing power $\mathrm{A}=\mathrm{A}_{1}-\mathrm{A}_{0}$.

\subsubsection{Anti-Acetylcholinesterase Activity}

The method of Wang et al. was used with modification [22]. Sample solutions with concentrations of $0.5,1.0,1.5,2.0,3.0$, and $4.0 \mathrm{mg} / \mathrm{mL}$ were prepared from the alcoholsoluble extracts. In a test tube, $2900 \mu \mathrm{L}$ of phosphate working buffer solution $(0.1 \mathrm{M}, \mathrm{pH}$ 8.0), $20 \mu \mathrm{L}$ of acetylcholinesterase solution $(0.6 \mathrm{U} / \mathrm{mL})$, and $100 \mu \mathrm{L}$ of a sample solution were added, fully mixed, and preheated in a water bath at $37^{\circ} \mathrm{C}$ for $2 \mathrm{~min}$. Subsequently, $50 \mu \mathrm{L}$ of 5,5'-dithiobis-2-nitrobenzoic acid $(15 \mathrm{mM})$ solution and $50 \mu \mathrm{L}$ of acetylthiocholine iodide $(15 \mathrm{mM})$ solution was added sequentially, and the reaction was conducted in a water bath at $37^{\circ} \mathrm{C}$ for $20 \mathrm{~min}$. The reaction was terminated by adding $1 \mathrm{~mL}$ of $4 \%$ sodium dodecyl sulfate solution; the absorbance was rapidly measured at $412 \mathrm{~nm}$ and denoted as $\mathrm{A}_{1}$. Due to the alcohol-soluble extract solution having color, the sample background was deducted. Subsequently, $20 \mu \mathrm{L}$ of phosphate working buffer solution was used instead of the acetylcholinesterase solution, and the absorbance was measured, which was denoted $\mathrm{A}_{2}$. Due to the sample solution being prepared with anhydrous ethanol, which might decrease the enzyme activity, the sample solution was substituted by $100 \mu \mathrm{L}$ of anhydrous ethanol to serve as the control, and the absorbance was measured, which was denoted as $\mathrm{A}_{3}$. Finally, a blank control group was prepared by replacing the sample solution with $100 \mu \mathrm{L}$ of the phosphate working buffer solution and the absorbance was measured, which was denoted as $\mathrm{A}_{4}$.

$$
\text { Acetylcholinesterase activity inhibition rate }(\%)=\frac{A_{3}-\left(A_{1}-A_{2}\right)}{A_{4}} \times 100 \% \text {. }
$$

\subsubsection{Anti- $\alpha$-Glucosidase Activity}

The method of Ting et al. was employed with modifications [23]. Appropriate amounts of the alcohol-soluble extracts were dissolved in ethanol to prepare sample solutions with concentrations of $0.1,0.2,0.4,0.6,0.8$, and $1.0 \mathrm{mg} / \mathrm{mL}$. Subsequently, $1600 \mu \mathrm{L}$ of phosphate working buffer solution $(0.1 \mathrm{M} \mathrm{pH} 8.0), 220 \mu \mathrm{L}$ of acetylcholinesterase solution $(0.6 \mathrm{U} / \mathrm{mL})$, and $10 \mu \mathrm{L}$ of a sample solution were added to a test tube, mixed well, and preheated at $37^{\circ} \mathrm{C}$ for $10 \mathrm{~min}$. Following this, $150 \mu \mathrm{L}$ of p-nitrophenyl- $\beta$-d-galactopyranoside solution $(2.5 \mathrm{mM})$ was added and heated in a water bath at $37^{\circ} \mathrm{C}$ for $20 \mathrm{~min}$; finally, $1 \mathrm{~mL}$ of $\mathrm{Na}_{2} \mathrm{CO}_{3}$ solution $(0.2 \mathrm{M})$ was added to terminate the reaction; the absorbance value was measured rapidly at a wavelength of $405 \mathrm{~nm}$ and was denoted as $\mathrm{A}_{1}$. The sample background was deducted using $220 \mu \mathrm{L}$ of the phosphate working buffer solution instead 
of the acetylcholinesterase solution, and the absorbance value was measured, which was denoted as $\mathrm{A}_{2}$. Subsequently, $10 \mu \mathrm{L}$ of anhydrous ethanol was used to replace the sample solution as the control, and the absorbance was measured, which was denoted as $\mathrm{A}_{3}$. Finally, the sample solution was substituted with $10 \mu \mathrm{L}$ of the phosphate working buffer solution as the control group, and the absorbance value was registered as $\mathrm{A}_{4}$.

$$
A-\text { glucosidase activity inhibition rate }(\%)=\frac{A_{3}-\left(A_{1}-A_{2}\right)}{A_{4}} \times 100 \% .
$$

\subsubsection{Data Processing}

The experiments were repeated thrice and the results are expressed as mean \pm standard deviation. One-way analysis of variation was performed using SPSS software $(p<0.05$, significant difference). Moreover, $50 \%$ Inhibitory Concentration ( $\left.\mathrm{IC}_{50}\right)$ was calculated using GraphPad Prism 8.

\section{Results}

\subsection{Antioxidation Ability}

3.1.1. DPPH Free Radical Scavenging Capacity

The agarwood produced by both $A$. sinensis and A. crassna showed strong elimination of DPPH radicals. The clearance rate of DPPH free radicals tended to increase with increasing alcohol-soluble extract concentrations from $0.2 \mathrm{mg} / \mathrm{mL}$ to $2 \mathrm{mg} / \mathrm{mL}$ (Figure 2); thus, the scavenging rates showed some dose dependence. The $\mathrm{IC}_{50}$ values of the $\mathrm{DPPH}$ free radical by the artificial agarwood samples were $0.4127 \mathrm{mg} / \mathrm{mL}$ (C12), $0.5632 \mathrm{mg} / \mathrm{mL}$ (C18), $0.7487 \mathrm{mg} / \mathrm{mL}$ (A6), $0.5763 \mathrm{mg} / \mathrm{mL}$ (A12), $0.3902 \mathrm{mg} / \mathrm{mL}$ (A18), and of the wild agarwood, YS, was $0.3070 \mathrm{mg} / \mathrm{mL}$. All batches (five) of the artificial agarwood had excellent $\mathrm{DPPH}$ free radical clearance rates. $\mathrm{The}^{\mathrm{IC}} \mathrm{C}_{50}$ value of DPPH radicals for $\mathrm{A} 18$ was the smallest among the sample groups, indicating that with $50 \%$ scavenging rate, its natural active ingredient was more specific and effective in clearing DPPH radicals than those of the others.

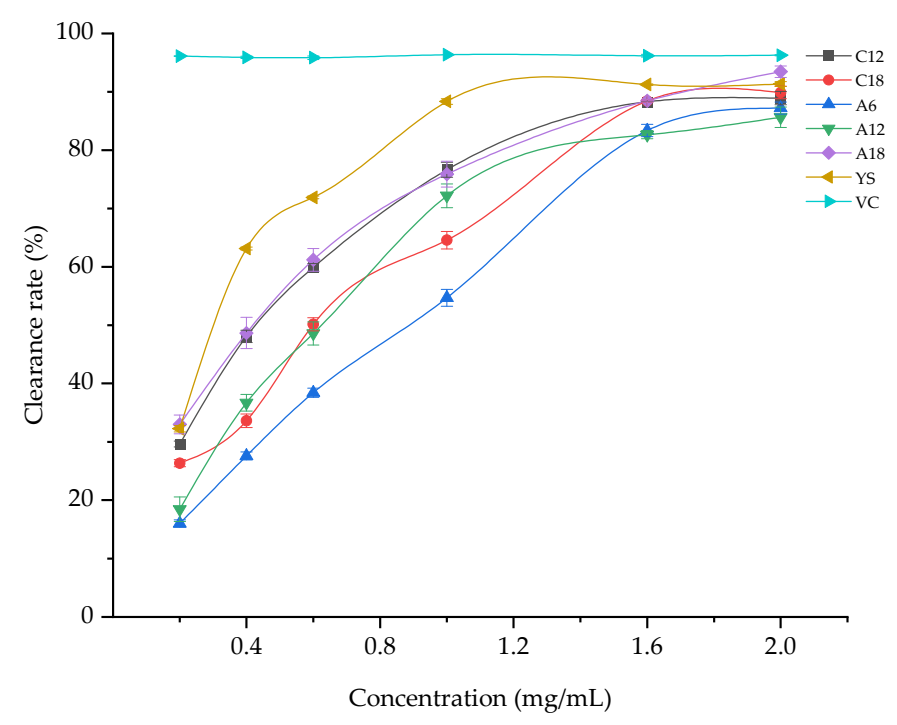

Figure 2. DPPH free radical clearance rate variation with extract concentration (C12 and C18 represented agarwood produced by $A$. crassna after 12 and 18 months of inoculation, respectively; A6-A18 represented agarwood produced by A. sinensis after 6, 12, and 18 months of inoculation, respectively; YS and VC represented wild agarwood and ascorbic acid, respectively).

The highest DPPH free radical scavenging rates were achieved when the alcohol-soluble extract concentration was $2 \mathrm{mg} / \mathrm{mL}$. The corresponding rates of the samples and controls (VC and YS) followed the order VC $(96.27 \pm 0.09 \%)>\mathrm{A} 18(93.45 \pm 0.98 \%)>\mathrm{YS}(91.34 \pm 0.41 \%)$ 
$>$ C18 $(89.88 \pm 1.07 \%)>$ C12 $(88.92 \pm 1.15 \%)>$ A6 $(87.20 \pm 1.03 \%)>$ A12 (85.62 $\pm 1.76 \%)$ (Table 2), and all sample batches exhibited significant scavenging of DPPH free radicals. Moreover, the effect of VC on scavenging DPPH free radicals was significantly superior to all batches of agarwood $(p<0.05)$. The DPPH radical clearance rates of $\mathrm{C} 12, \mathrm{C} 18, \mathrm{~A} 6, \mathrm{~A} 12$, and A18 were $97.35 \%, 98.40 \%, 95.47 \%, 93.74 \%$, and $102.31 \%$ of that of $Y S$, respectively. The DPPH free radical scavenging effect of C18 was better than that of $\mathrm{C} 12$, whereas it was not significantly different from that of YS $(p<0.05)$. Moreover, the ability of A18 to scavenge DPPH free radicals was significantly higher than those of YS, C12, C18, A6, and A12 $(p<0.05)$. The results indicated that the fungal inducer not only improved the yield of this artificial agarwood and shortened the agarwood formation time but also made its ability to scavenge DPPH free radicals comparable to that of the wild agarwood. In terms of the inoculation time, the agarwood produced by 18 months of inoculation had a superior DPPH free radical scavenging rate to those produced by 6 and 12 months of inoculation. Interestingly, the DPPH free radical elimination effect of the $A$. sinensis-generated agarwood was better than that of the A. crassna-produced agarwood generated after 18 months of inoculation, and was even higher than that of the wild agarwood.

Table 2. DPPH free radical scavenging capacity of five batches and controls.

\begin{tabular}{ccc}
\hline Samples & $\begin{array}{c}\text { Alcohol-Soluble Extract Solution } \\
\text { Concentration } \mathbf{( m g / m L )}\end{array}$ & $\begin{array}{c}\text { DPPH Free Radical Scavenging } \\
\text { Capacity (\%) }\end{array}$ \\
\hline C12 & 2 & $88.92 \pm 1.15^{\mathrm{d}}$ \\
C18 & 2 & $89.88 \pm 1.07^{\mathrm{c}}$ \\
A6 & 2 & $87.20 \pm 1.03^{\mathrm{d}, \mathrm{e}}$ \\
A12 & 2 & $85.62 \pm 1.76^{\mathrm{e}}$ \\
A18 & 2 & $93.45 \pm 0.98^{\mathrm{b}}$ \\
YS & 2 & $91.34 \pm 0.41^{\mathrm{c}}$ \\
VC & 2 & $96.27 \pm 0.09^{\mathrm{a}}$ \\
\hline
\end{tabular}

Each value represents the mean $\pm \mathrm{SD}(n=3) ; \mathrm{SD}$, standard deviation. At $p<0.05$ according to one-way analysis of variation, mean values followed by different letters are significantly different from each other; mean values followed by one letter identical are not significantly different from each other.

\subsection{2. $\mathrm{ABTS}^{+}$Free Radical Scavenging Capacity}

The clearance rate of $\mathrm{ABTS}^{+}$free radicals increased with increasing mass concentration of the alcohol-soluble extract from 0.2 to $2 \mathrm{mg} / \mathrm{mL}$ (Figure 3). Moreover, the scavenging activity showed some dose dependence, with the scavenging rate initially increasing below sample concentration of $1.6 \mathrm{mg} / \mathrm{mL}$ and subsequently increasing gradually. The $\mathrm{IC}_{50}$ values of $\mathrm{ATBS}^{+}$free radical by the artificial (five samples) and wild agarwood were $0.8401 \mathrm{mg} / \mathrm{mL}$ (C12), $0.9317 \mathrm{mg} / \mathrm{mL}$ (C18), $1.1710 \mathrm{mg} / \mathrm{mL}$ (A6), $0.8999 \mathrm{mg} / \mathrm{mL}$ (A12), $0.4472 \mathrm{mg} / \mathrm{mL}$ (A18), and $0.2368 \mathrm{mg} / \mathrm{mL}$ (YS), respectively. The $\mathrm{IC}_{50}$ value of $\mathrm{ABTS}^{+}$free radicals for A18 was the smallest among the artificial agarwood samples, indicating that $50 \%$ scavenging rate contains a natural active ingredient that is more specific than those of the other samples. 


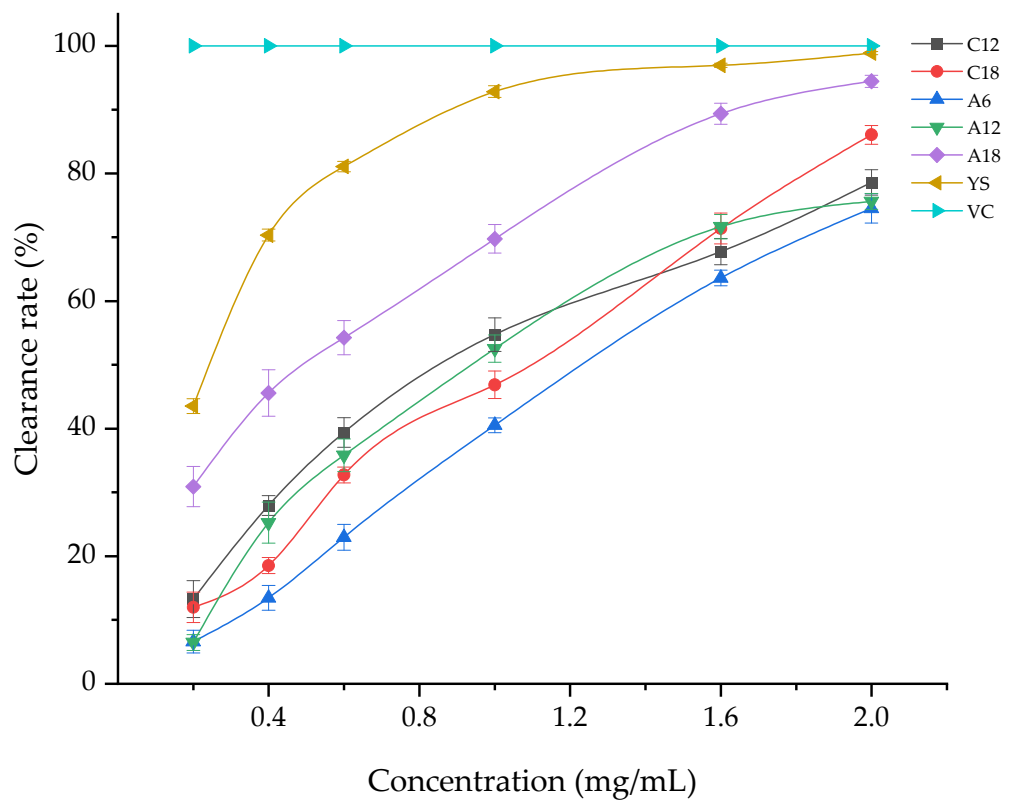

Figure 3. $\mathrm{ABTS}^{+}$free radical clearance rate variation with extract concentration $(\mathrm{C} 12$ and $\mathrm{C} 18$ represented agarwood produced by $A$. crassna after 12 and 18 months of inoculation, respectively; A6-A18 represented agarwood produced by A. sinensis after 6, 12, and 18 months of inoculation, respectively; YS and VC represented wild agarwood and ascorbic acid, respectively).

When the sample concentration was $2 \mathrm{mg} / \mathrm{mL}$, the maximum $\mathrm{ABTS}^{+}$free radical scavenging rates of all sample batches (five) and controls followed the order VC (100\%) > YS $(98.87 \pm 0.25 \%)>\mathrm{A} 18(94.44 \pm 0.94 \%)>\mathrm{C} 18(86.06 \pm 1.47 \%)>\mathrm{C} 12(78.59 \pm 2 \%)>\mathrm{A} 12$ $(75.62 \pm 1.25 \%)>\mathrm{A} 6(74.53 \pm 2.31 \%)$ (Table 3$)$. This trend suggests the presence of natural active ingredients with a better clearance effect on $\mathrm{ABTS}^{+}$free radicals. The $\mathrm{ABTS}^{+}$radical scavenging rates of $\mathrm{C} 12, \mathrm{C} 18, \mathrm{~A} 6, \mathrm{~A} 12$, and, A18 were $79.49 \%, 87.93 \%, 75.38 \%, 76.48 \%$, and $95.52 \%$ of that of YS, respectively; the ability of C18 to clear ABTS ${ }^{+}$free radicals was significantly higher than that of $\mathrm{C} 12(p<0.05)$. The $\mathrm{ABTS}^{+}$free radical clearance rate of A18 was significantly superior to those of $\mathrm{C} 12, \mathrm{C} 18, \mathrm{~A} 6$, and A12 $(p<0.05)$. Interestingly, in terms of the inoculation time, $\mathrm{ABTS}^{+}$free radical clearance effects of the agarwood produced by both A. sinensis and A. crassna increased with the inoculation time. This suggest that the agarwood formed after 18 months of inoculation had a better ability to scavenge ABTS $^{+}$free radicals than those formed after 6 and 12 months. This was particularly for the agarwood generated by $A$. sinensis, whose $\mathrm{ABTS}^{+}$free radical scavenging rate reached $95.52 \%$ of that of the wild agarwood, showing that the two rates are almost comparable.

Table 3. The $\mathrm{ABTS}^{+}$free radical scavenging capacity of five batches and controls.

\begin{tabular}{ccc}
\hline Samples & $\begin{array}{c}\text { Alcohol-Soluble Extract Solution } \\
\text { Concentration }(\mathbf{m g} / \mathbf{m L})\end{array}$ & $\begin{array}{c}\text { ABTS }^{+} \text {Free Radical Scavenging } \\
\text { Capacity (\%) }\end{array}$ \\
\hline C12 & 2 & $78.59 \pm 2^{\mathrm{d}}$ \\
C18 & 2 & $86.06 \pm 1.47^{\mathrm{c}}$ \\
A6 & 2 & $74.53 \pm 2.31^{\mathrm{e}}$ \\
A12 & 2 & $75.62 \pm 1.25^{\mathrm{d}, \mathrm{e}}$ \\
A18 & 2 & $94.44 \pm 0.94^{\mathrm{b}}$ \\
YS & 2 & $98.87 \pm 0.25^{\mathrm{a}}$ \\
VC & 2 & $100^{\mathrm{a}}$ \\
\hline
\end{tabular}

Each value represents the mean $\pm \mathrm{SD}(n=3)$; SD, standard deviation. At $p<0.05$ according to one-way analysis of variation, mean values followed by different letters are significantly different from each other; mean values followed by one letter identical are not significantly different from each other. 


\subsubsection{Total Reducing Power}

The total reducing capacity of the alcohol-soluble extract increased with the increase in its mass concentration from 0.5 to $3.5 \mathrm{mg} / \mathrm{mL}$ (Figure 4), and the total reducing capacity exhibited some dose dependence.

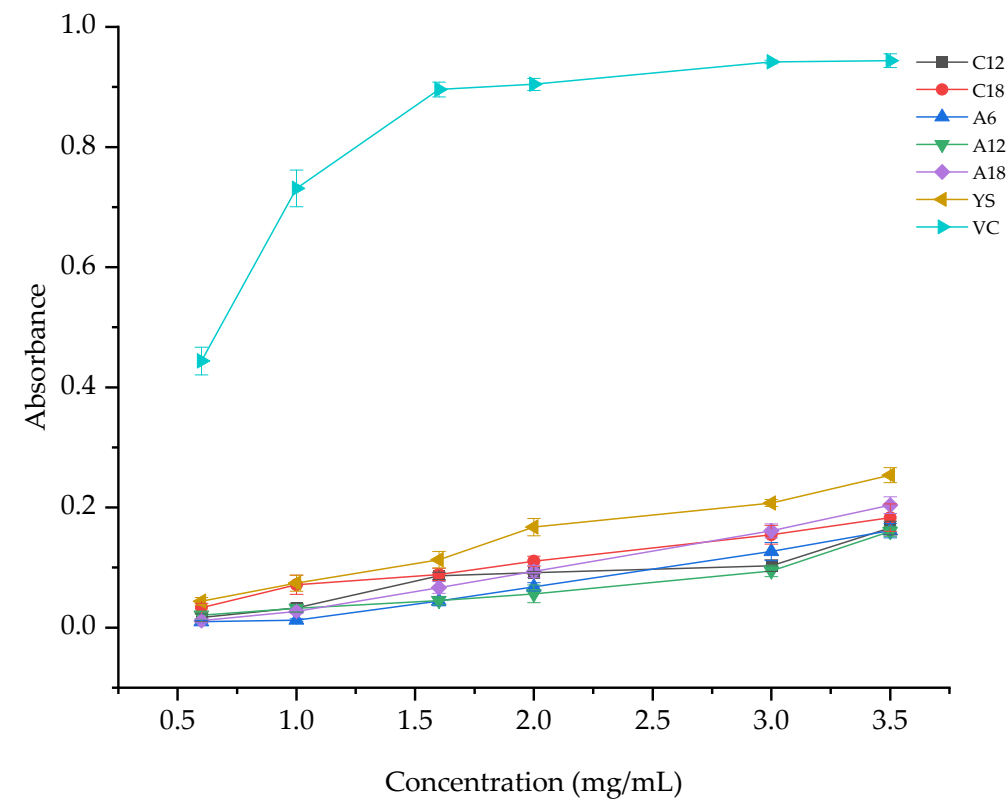

Figure 4. Total reducing power variation with extract concentration (C12 and C18 represented agarwood produced by A. crassna after 12 and 18 months of inoculation, respectively; A6-A18 represented agarwood produced by $A$. sinensis after 6, 12, and 18 months of inoculation, respectively; YS and VC represented wild agarwood and ascorbic acid, respectively).

When the sample concentration was $3.5 \mathrm{mg} / \mathrm{mL}$, the total reducing powers of all batches (five) and controls followed the order VC $(0.9437 \pm 0.0116)>\mathrm{YS}(0.2537 \pm 0.0127)>$ $\mathrm{A} 18(0.2037 \pm 0.0140)>\mathrm{C} 18(0.1830 \pm 0.0230)>\mathrm{C} 12(0.1657 \pm 0.0115)>\mathrm{A} 6(0.1613 \pm 0.0121)$ $>$ A12 $(0.1600 \pm 0.0085)$ (Table 4). The total reducing power of C18, C18, A6, A12, and A18 were $65.31 \%, 72.13 \%, 63.58 \%, 63.07 \%$, and $80.29 \%$ of that of YS, respectively. The total reducing power of $\mathrm{C} 18$ was superior to that of $\mathrm{C} 12$; the total reducing power of $\mathrm{A} 18$ was greater than that of $\mathrm{C} 18$, significantly higher than those of A6, A12, and $\mathrm{C} 12(p<0.05)$, and lower than that of $\mathrm{VC}$. The results indicate that the difference in the total reducing power of the agarwood produced by $A$. sinensis and A. crassna inoculated for 6 and 12 months was small. In comparison, the total reducing power of the agarwood generated after 18 months of inoculation was the highest. Moreover, for the same period, the agarwood produced by $A$. sinensis had superior total reducing power to that produced by A. crassna, and even reached $80.29 \%$ of that of the wild agarwood.

Table 4. The total reducing powers of all five batches and controls.

\begin{tabular}{ccc}
\hline Samples & $\begin{array}{c}\text { Alcohol-Soluble Extract Solution Concentration } \\
(\mathbf{m g} / \mathbf{m L})\end{array}$ & Total Reducing Power \\
\hline C12 & 3.5 & $0.1657 \pm 0.0115^{\mathrm{d}}$ \\
C18 & 3.5 & $0.1830 \pm 0.0230^{\mathrm{c}, \mathrm{d}}$ \\
A6 & 3.5 & $0.1613 \pm 0.0121^{\mathrm{d}}$ \\
A12 & 3.5 & $0.1600 \pm 0.0085^{\mathrm{d}}$ \\
A18 & 3.5 & $0.2037 \pm 0.0140^{\mathrm{c}}$ \\
YS & 3.5 & $0.2537 \pm 0.0127^{\mathrm{b}}$ \\
VC & 3.5 & $0.9437 \pm 0.0116^{\mathrm{a}}$ \\
\hline
\end{tabular}

Each value represents the mean $\pm \mathrm{SD}(n=3)$; SD, standard deviation. At $p<0.05$ according to one-way analysis of variation, mean values followed by different letters are significantly different from each other; mean values followed by one letter identical are not significantly different from each other. 


\subsection{Acetylcholinesterase Activity Inhibition}

The inhibitory ability of the alcohol-soluble extract on acetylcholinesterase activity increased with increasing mass concentration ranging from $0.5 \mathrm{mg} / \mathrm{mL}$ to $4 \mathrm{mg} / \mathrm{mL}$ (Figure 5). The $\mathrm{IC}_{50}$ values of acetylcholinesterase activity by the artificial (five) and wild agarwood were $0.3105 \mathrm{mg} / \mathrm{mL}$ (C12), $0.3600 \mathrm{mg} / \mathrm{mL}$ (C18), $0.2654 \mathrm{mg} / \mathrm{mL}$ (A6), $0.4274 \mathrm{mg} / \mathrm{mL}$ (A12), $0.3200 \mathrm{mg} / \mathrm{mL}$ (A18), and $0.1385 \mathrm{mg} / \mathrm{mL}$ (YS), respectively. These values indicated that the ability of A6 to inhibit acetylcholinesterase activity reached 50\% of required concentration which was lower in the sample groups, and that the natural ingredients of A6 were more specific than those of the others.

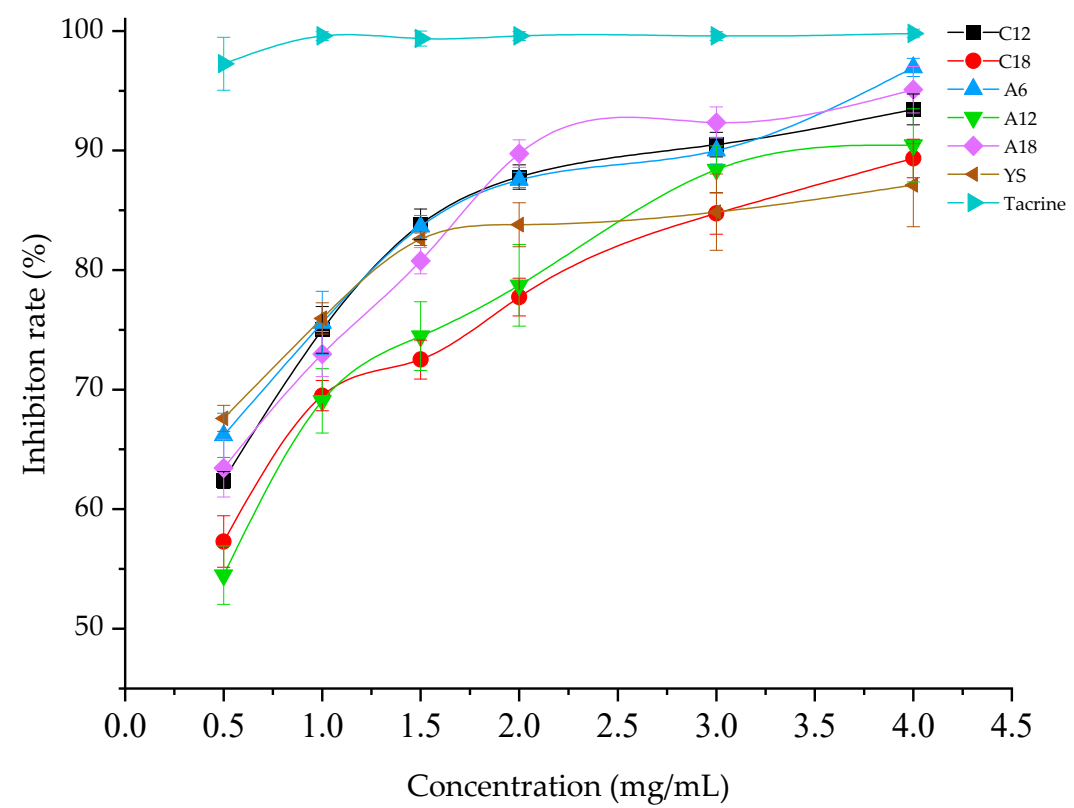

Figure 5. Inhibition rate of acetylcholinesterase activity variation with extract concentration (C12 and C18 represented agarwood produced by A. crassna after 12 and 18 months of inoculation, respectively; A6-A18 represented agarwood produced by A. sinensis after 6, 12, and 18 months of inoculation, respectively; YS represented wild agarwood).

The maximum inhibition rates of acetylcholinesterase activity by the samples and controls at the concentration of $4 \mathrm{mg} / \mathrm{mL}$ followed the order Tacrine $(99.79 \pm 0.37 \%)>\mathrm{A} 6$ $(96.95 \pm 0.76 \%)>\mathrm{A} 18(95.09 \pm 1.95 \%)>\mathrm{C} 12(93.44 \pm 1.28 \%)>\mathrm{A} 12(90.44 \pm 3.06 \%)>\mathrm{C} 18$ $(89.34 \pm 1.61 \%)>$ YS $(87.11 \pm 3.48 \%)$ (Table 5$)$. These rates were $107.27 \%, 102.56 \%, 111.30 \%$, $103.82 \%$, and $109.16 \%$ of that of natural agarwood, respectively. The ability of A6 to inhibit acetylcholinesterase activity was not significantly different from that of the clinical drug, Tacrine $(p<0.05)$; the acetylcholinesterase inhibitory activity of A6 was $3.51 \%, 7.61 \%, 6.51 \%$, $1.86 \%$, and $9.87 \%$ higher than that of $\mathrm{C} 12, \mathrm{C} 18, \mathrm{~A} 12, \mathrm{~A} 18$, and YS, respectively. The results indicated that the natural components in all five batches of artificial agarwood inhibited acetylcholinesterase activity efficiently and were superior to those of the wild agarwood, thus indicating their potential application for the development of acetylcholinesterase inhibitors. 
Table 5. The inhibition rates of acetylcholinesterase activity in all five batches and controls.

\begin{tabular}{ccc}
\hline Samples & $\begin{array}{c}\text { Alcohol-Soluble Extract Solution } \\
\text { Concentration }(\mathbf{m g} / \mathbf{m L})\end{array}$ & $\begin{array}{c}\text { Acetylcholinesterase Activity } \\
\text { Inhibition }(\%)\end{array}$ \\
\hline C12 & 4 & $93.44 \pm 1.28^{\mathrm{b}, \mathrm{c}}$ \\
C18 & 4 & $89.34 \pm 1.61^{\mathrm{d}}$ \\
A6 & 4 & $96.95 \pm 0.76^{\mathrm{a}, \mathrm{b}}$ \\
A12 & 4 & $90.44 \pm 3.06^{\mathrm{c}, \mathrm{d}}$ \\
A18 & 4 & $95.09 \pm 1.95^{\mathrm{b}}$ \\
YS & 4 & $87.11 \pm 3.48^{\mathrm{d}}$ \\
Tacrine & 4 & $99.79 \pm 0.37^{\mathrm{a}}$ \\
\hline
\end{tabular}

Each value represents the mean $\pm \mathrm{SD}(n=3)$; SD, standard deviation. At $p<0.05$ according to one-way analysis of variation, mean values followed by different letters are significantly different from each other; mean values followed by one letter identical are not significantly different from each other.

\section{3. $\alpha$-Glucosidase Activity Inhibition}

In this study, all sample batches presented excellent inhibition rates of $\alpha$-glucosidase activity. The inhibition rate of $\alpha$-glucosidase activity of the alcohol-soluble extract increased with increasing mass concentration from $0.1 \mathrm{mg} / \mathrm{mL}$ to $1 \mathrm{mg} / \mathrm{mL}$ (Figure 6), and the inhibitory activity displayed a dose-dependent effect. The $\mathrm{IC}_{50}$ values of $\alpha$-glucosidase activity by the artificial (five samples) and wild agarwood were $0.4326 \mathrm{mg} / \mathrm{mL}$ (C12), $0.3430 \mathrm{mg} / \mathrm{mL}$ (C18), $0.5468 \mathrm{mg} / \mathrm{mL}$ (A6), $0.2824 \mathrm{mg} / \mathrm{mL}$ (A12), $0.2920 \mathrm{mg} / \mathrm{mL}$ (A18), and $0.1564 \mathrm{mg} / \mathrm{mL}$ (YS), respectively. These indicate that the ability of A12 to inhibit acetylcholinesterase activity reached $50 \%$ of the required concentration which was lower in artificial agarwood, and that the natural ingredients of A12 were more effective than those of the other samples.

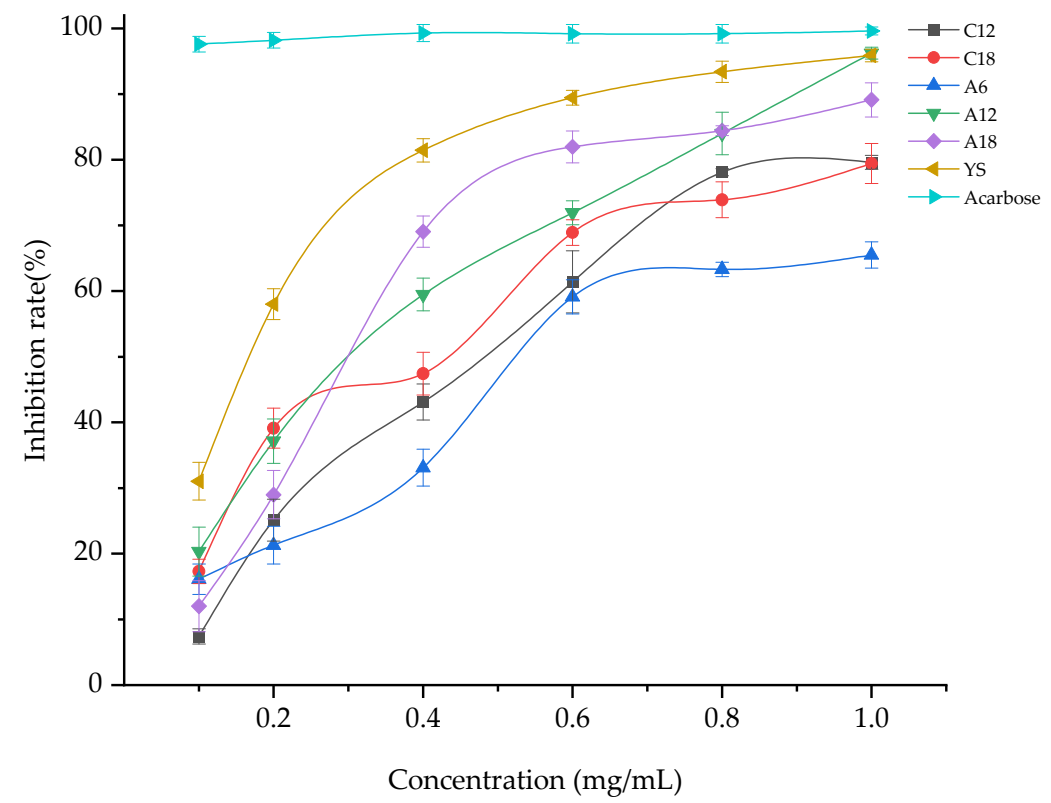

Figure 6. Inhibition rate of $\alpha$-glucosidase activity variation with extract concentration (C12 and C18 represented agarwood produced by A. crassna after 12 and 18 months of inoculation, respectively; A6-A18 represented agarwood produced by A. sinensis after 6, 12, and 18 months of inoculation, respectively; YS represented wild agarwood).

When the sample concentration was $1 \mathrm{mg} / \mathrm{mL}$, the inhibition rates of $\alpha$-glucosidase activity of the samples and controls followed the order acarbose $(99.60 \pm 0.60 \%)>\mathrm{A} 12$ $(96.24 \pm 0.89 \%)>$ YS $(95.87 \pm 0.94 \%)>$ A18 $(89.12 \pm 2.62 \%)>\mathrm{C} 12(79.60 \pm 1.07 \%)>\mathrm{C} 18$ $(79.42 \pm 3.05 \%)>$ A6 $(65.50 \pm 2.00 \%)$ (Table 6). The inhibition rates of $\alpha$-glucosidase activity of $\mathrm{C} 12, \mathrm{C} 18, \mathrm{~A} 6, \mathrm{~A} 12$, and $\mathrm{A} 18$ were $83.03 \%, 68.78 \%, 68.32 \%, 100.39 \%$, and $92.96 \%$ 
of that of YS, respectively. The inhibition rates of $\alpha$-glucosidase of A12 and A18 were significantly higher than those of C12 and C18 $(p<0.05)$. The ability of A12 to inhibit $\alpha$-glucosidase activity was significantly superior to those of A18, C12, C18, and A6, and was not significantly different from that of YS $(p<0.05)$. The results indicated that although the artificial agarwood required a short timeframe, its $\alpha$-glucosidase activity inhibition rate reached more than $68.32 \%$ of that of the wild agarwood. Moreover, the inhibition rate of $\alpha$-glucosidase activity of the agarwood produced by $A$. sinensis after 12 and 18 months of inoculation reached $100.39 \%$ and $92.96 \%$ of that of wild agarwood, which shows they are comparable. The inhibition rate of $\alpha$-glucosidase activity of the agarwood generated by $A$. sinensis and $A$. crassna first increased and subsequently decreased with increasing inoculation time. Moreover, the $\alpha$-glucosidase activity inhibition of the agarwood produced by $A$. sinensis was superior to that of the agarwood produced by A. crassna at the same inoculation time. Therefore, the best inhibition of $\alpha$-glucosidase activity was achieved by agarwood from $A$. sinensis inoculated for 12 months, which were $7.12 \%, 16.64 \%, 16.82 \%$, and $30.74 \%$ higher than those of A18, C12, C18, and A6, respectively.

Table 6. The inhibition rates of acetylcholinesterase activity in all five batches and controls.

\begin{tabular}{ccc}
\hline Samples & $\begin{array}{c}\text { Alcohol-Soluble Extract Solution } \\
\text { Concentration } \mathbf{( m g / m L )}\end{array}$ & $\begin{array}{c}\alpha \text {-Glucosidase Activity } \\
\text { Inhibition (\%) }\end{array}$ \\
\hline C12 & 1 & $79.60 \pm 1.07^{\mathrm{d}}$ \\
C18 & 1 & $79.42 \pm 3.05^{\mathrm{d}}$ \\
A6 & 1 & $65.50 \pm 2.00^{\mathrm{e}}$ \\
A12 & 1 & $96.24 \pm 0.89^{\mathrm{b}}$ \\
A18 & 1 & $89.12 \pm 2.62^{\mathrm{c}}$ \\
YS & 1 & $95.87 \pm 0.94^{\mathrm{b}}$ \\
Acarbose & 1 & $99.60 \pm 0.60^{\mathrm{a}}$ \\
\hline
\end{tabular}

Each value represents the mean $\pm \mathrm{SD}(n=3)$; SD, standard deviation. At $p<0.05$ according to one-way analysis of variation, mean values followed by different letters are significantly different from each other; mean values followed by one letter identical are not significantly different from each other.

\section{Discussion}

Excessive free radicals such as $\mathrm{O}_{2}{ }^{--}, \mathrm{OH}^{*}$, and $\mathrm{NO}$ in the human body may originate from diet, smoking, drugs, inflammation, UV light exposure, air pollutants, stress, and alcohol [24]. Moreover, they can cause damage to biological macromolecules, such as DNA, proteins, and lipids, resulting in aging, allergies, cardiovascular diseases, inflammation, and cancer, which are harmful to human health. Many antioxidants can scavenge free radicals and reduce the damage caused by them to the human body, and several studies have shown that agarwood possesses antioxidant capacity. $\beta$-Caryophyllene is a common type of sesquiterpene in agarwood, and it has a remarkable clearance effect on DPPH radicals [7]. Wang et al. (2018) used gas chromatography-mass spectrometry to analyze the essential oil of agarwood and identified various sesquiterpenes and chromones. They also investigated the inhibition of DPPH radicals by the essential oil, indicating that the essential oil of agarwood can eliminate DPPH free radicals, and the $\mathrm{IC}_{50}$ value was obtained as $52.34 \mathrm{mg} / \mathrm{mL}$ [25]. Artificial agarwood produced by this fungal inducer, whose $\mathrm{IC}_{50}$ values for the clearance of DPPH free radicals were lower than that of the above mentioned essential oil [25], show that the natural ingredients of these artificial agarwood samples have stronger ability to scavenge DPPH free radicals. Li et al. (2020) demonstrated that several chromones, such as 6,7-dimethoxy-2-(2-phenylethyl)chromone, 6-hydroxy-2-(2phenylethyl)chromone, and 6,8-dihydroxy-2-(2-phenylethyl)chromone, commonly found in agarwood, can reduce $\mathrm{ABTS}^{+}$radicals [20].

All sample batches had significant antioxidant capacity, indicating their potential application for the development of oxidation inhibitors. Specifically, the agarwood produced from $A$. sinensis inoculated for 18 months had the smallest $\mathrm{IC}_{50}$ values of DPPH and $\mathrm{ABTS}^{+}$ radicals as well as possessing the highest reducing power than the remaining four batches of samples, thus its antioxidant capacity was best in the sample groups. 
Alzheimer's disease is a neurological disorder characterized by cognitive dysfunction and behavioral impairment, and with approximately 7.7 million new cases worldwide each year [26], it has become a difficult global problem. Acetylcholinesterase inhibitors can alleviate the symptoms of Alzheimer's disease; however, the current ones in clinical use are accompanied by various side effects, such as dizziness, fatigue, and cardiac arrhythmias [27-29]. Agarwood has been used as a valuable herbal medicine since ancient times that is used to treat allergies, stomach problems, coughs, rheumatism, and gout; promote blood circulation; relieve pain, warm the middle energy and stop vomiting; regulate breathing, and relieve asthma [18]. If anti-acetylcholinesterase-active drugs could be developed from agarwood, it will be possible to avoid the above-mentioned adverse effects, and many studies have confirmed that agarwood contains several active components that can inhibit acetylcholinesterase. $\mathrm{Li}$ et al. (2014) tested the anti-acetylcholinesterase activity of 16 chromones isolated from agarwood using an artificial hole-punching induction method and found that 12 chromones inhibited acetylcholinesterase from $10.1 \pm 0.9$ to $46.1 \pm 0.9 \%$ [13]. In the study of Liao et al. (2017), agarwood generated by artificial hole (four-year) induction was separated, and the anti-acetylcholinesterase activity was measured, which showed that five tetrahydrochromones and an oxidoagarochromone inhibited acetylcholinesterase activity by 17.5-47.9\% [30]. Li et al. (2015) found that in agarwood obtained using the hole-punching method, five sesquiterpenes inhibited acetylcholinesterase activity by $10.3 \pm 0.9-20.8 \pm 0.9 \%$ [15].

However, with a manual hole-punching method, the yield of agarwood is extremely low, primarily near the cut, and the agarwood production cycle is extremely long to meet the needs of industrialization. In this study, fungi were infused into the xylem of Aquilaria trees, and the fungal sap flowed through the entire tree, resulting in whole-tree agarwood formation, which expanded the yield of agarwood, and thus, can solve the current scenario of insufficient yield. If the fungal inoculant induces the production of agarwood as a drug that inhibits acetylcholinesterase activity, then from the perspective of better economy, $A$. sinensis is selected as the tree species to be inoculated by the fungal inducer. Moreover, 6 months of inoculation is chosen as the better harvesting period than 12 and 18 months.

According to the International Diabetes Federation, in 2015, 415 million people have suffered from diabetes worldwide [31]. $\alpha$-glucosidase inhibitors are a class of oral hypoglycemic agents; however, the currently used ones, such as acarbose and miglitol can cause gastrointestinal problems [32]. If $\alpha$-glucosidase inhibitors can be prepared using natural active ingredients, the side effects described above may be avoided. Many studies have revealed that agarwood contains natural active ingredients that can inhibit $\alpha$-glucosidase. Sukito et al. (2020) demonstrated that the inhibition of the $\alpha$-glucoside effect reached $63.62 \%$ with $100 \mu \mathrm{g} / \mathrm{mL}$ acetone extract of agarwood [33]. Li et al. (2019) proved that agarozizanol E, jinkohol I, jinkohol II, and isokhusenol were sesquiterpenes from agarwood that have significant inhibitory effects on acetylcholine activity [34]. Mi et al. (2021) further established that agarwood has various 2-(2-phenylethyl) chromones, such as 5,8-dihydroxy2-(2-phenylethyl)chromone, 6-hydroxy-8-methylsulfinyl-2-(2-phenylethyl)chromone, and 8-dihydrox-y-2-[2-(2-hydroxyphenyl)ethyl]chromone, which exhibit excellent inhibition of $\alpha$-glucoside activity [35]. All artificial agarwood samples presented excellent inhibition activity against $\alpha$-glucosidase and effectively reduced the decomposition of polysaccharides and sucrose into glucose, so that the absorption of sugar is slowed down accordingly. This suggests that the natural active ingredients of fungus-induced agarwood are important for the prevention and treatment of diabetes, and that the use of agarwood for the preparation of $\alpha$-glucosidase inhibitors will reduce the incidence of side effects. The $\mathrm{IC}_{50}$ values of $\alpha$-glucosidase activity of agarwood produced by $A$. sinensis during the same inoculation period were much lower than those of agarwood produced by $A$. crassna. If this artificial agarwood is used as a drug for the production of $\alpha$-glucosidase inhibitors, then from the perspective of better economy, $A$. sinensis is more suitable as a tree species for inoculation with the fungal inducer. Moreover, 12 months of inoculation for producing artificial agarwood is a better harvesting period than 6 and 18 months. 


\section{Conclusions}

In this paper, the clearance rates of DPPH and $\mathrm{ABTS}^{+}$radicals, total reducing power, anti-acetylcholinesterase, and anti- $\alpha$-glucosidase activity were determined for comparing the biological activity of the artificial and wild agarwood. The results indicated that with $2 \mathrm{mg} / \mathrm{mL}$ alcohol-soluble extracts, the DPPH free radical scavenging rate of the artificial agarwood samples were $93.74-102.31 \%$ of that of the wild agarwood, and the ABTS ${ }^{+}$free radical clearance rates of the artificial agarwood samples were $75.38-95.52 \%$ of that of the natural agarwood. With $3.5 \mathrm{mg} / \mathrm{mL}$ alcohol-soluble extracts, the artificial agarwood samples achieved a total reducing power of $63.07-80.29 \%$ of the wild agarwood. With $4 \mathrm{mg} / \mathrm{mL}$ alcohol-soluble extracts, the acetylcholinesterase activity inhibition rates of the artificial agarwood samples were $102.56-109.16 \%$ of the wild agarwood. With $1 \mathrm{mg} / \mathrm{mL}$ alcohol-soluble extracts, the $\alpha$-glucosidase activity and the inhibition rates of the artificial agarwood samples were $68.32-100.39 \%$ of that of the wild agarwood. The agarwood samples produced using $A$. sinensis inoculated for 6,12 , and 18 months presented the best acetylcholinesterase activity inhibition rate, $\alpha$-glucosidase activity inhibition rate, and antioxidant activity, respectively. The results suggest that these artificial agarwood samples have the potential to develop products that can fight oxidation, and delay Alzheimer's disease and treat diabetes.

Supplementary Materials: The following are available online at https:/ /www.mdpi.com/article/10 .3390/f12111532/s1, Figure S1: Inoculation of Aquilaria trees and sample collection, Figure S2: The physicochemical chromogenic reactions of samples and standard agarwood.

Author Contributions: Conceptualization, Y.F. and S.M.; methodology, S.M.; software, P.W.; validation, Y.F., S.M. and P.W.; formal analysis, Z.L.; investigation, M.Q.; resources, Y.L.; data curation, Y.L., P.W. and M.Q.; writing—original draft preparation, S.M.; writing—review and editing, P.W.; visualization, S.M.; supervision, P.W.; project administration, Y.F.; funding acquisition, Y.F. All authors have read and agreed to the published version of the manuscript.

Funding: This research was supported by the National Natural Science Foundation of China grant number 31870540.

Institutional Review Board Statement: Not applicable.

Informed Consent Statement: Not applicable.

Data Availability Statement: Data is contained within the article.

Conflicts of Interest: The authors declare no conflict of interest.

\section{References}

1. Azren, P.D.; Azren, P.D.; Lee, S.Y.; Lee, S.Y.; Emang, D.; Emang, D.; Mohamed, R. History and perspectives of induction technology for agarwood production from cultivated Aquilaria in Asia: A review. J. For. Res. 2019, 30, 1-11. [CrossRef]

2. Lee, S.Y.; Mohamed, R. The Origin and Domestication of Aquilaria, an Important Agarwood-Producing Genus; Springer: Singapore, 2016; pp. 1-20.

3. Nor, A.M.; Said, A.A.; Majid, A.; Saidatul, J.; Yasmin, N. Comparison of chemical profile of selected gaharu oils from Peninsular Malaysia. Malays. J. Anal. Sci. 2008, 12, 338-340.

4. López-Sampson, A.; Page, T. History of Use and Trade of Agarwood. Econ. Bot. 2018, 72, 107-129. [CrossRef]

5. Nobuchi, T.; Somkid, S. Preliminary observation of Aquliaria crassna wood associated with the formation of aloeswood bult. Kyoto Univ. For. 1991, 63, 226-235.

6. Faizal, A.; Esyanti, R.R.; Aulianisa, E.N.; Iriawati; Santoso, E.; Turjaman, M. Formation of agarwood from Aquilaria malaccensis in response to inoculation of local strains of Fusarium solani. Trees 2017, 31, 189-197. [CrossRef]

7. Dahham, S.; Tabana, Y.; Iqbal, M.; Ahamed, M.; Ezzat, M.; Majid, A. The Anticancer, Antioxidant and Antimicrobial Properties of the Sesquiterpene $\beta$-Caryophyllene from the Essential Oil of Aquilaria crassna. Molecules 2015, 20, 11808-11829. [CrossRef]

8. Liu, Y.; Chen, H.; Yang, Y.; Zhang, Z.; Wei, J.; Meng, H.; Chen, W.; Feng, J.; Gan, B.; Chen, X.; et al. Whole-tree agarwood-inducing technique: An efficient novel technique for producing high-quality agarwood in cultivated Aquilaria sinensis trees. Molecules 2013, 18, 3086-3106. [CrossRef] [PubMed]

9. Rasool, S.; Mohamed, R. Understanding Agarwood Formation and Its Challenges; Springer: Singapore, 2016; pp. 39-56. 
10. Chen, H.; Yang, Y.; Xue, J.; Wei, J.; Zhang, Z.; Chen, H. Comparison of Compositions and Antimicrobial Activities of Essential Oils from Chemically Stimulated Agarwood, Wild Agarwood and Healthy Aquilaria sinensis (Lour.) Gilg Trees. Molecules 2011, 16, 4884-4896. [CrossRef]

11. Wang, C.; Wang, S.; Peng, D.; Yu, Z.; Guo, P.; Wei, J. Agarwood Extract Mitigates Intestinal Injury in Fluorouracil-Induced Mice. Biol. Pharm. Bull. 2019, 42, 1112-1119. [CrossRef]

12. Li, W.; Chen, H.; Wang, H.; Mei, W.; Dai, H. Natural products in agarwood and Aquilaria plants: Chemistry, biological activities and biosynthesis. Nat. Prod. Rep. 2021, 38, 528-565. [CrossRef]

13. Li, W.; Cai, C.; Dong, W.; Guo, Z.; Wang, H.; Mei, W.; Dai, H. 2-(2-Phenylethyl)chromone derivatives from Chinese agarwood induced by artificial holing. Fitoterapia 2014, 98, 117-123. [CrossRef]

14. Kuang, T.; Chen, H.; Kong, F.; Cai, C.; Yang, L.; Mei, W.; Dai, H. Three new 2-(2-phenylethyl)chromone derivatives from artificial holing agarwood of Aquilaria sinensis. Phytochem. Lett. 2018, 26, 96-100. [CrossRef]

15. Li, W.; Cai, C.H.; Guo, Z.K.; Wang, H.; Zuo, W.J.; Dong, W.H.; Mei, W.L.; Dai, H.F. Five new eudesmane-type sesquiterpenoids from Chinese agarwood induced by artificial holing. Fitoterapia 2015, 100, 44-49. [CrossRef]

16. Liao, G.; Mei, W.L.; Dong, W.H.; Li, W.; Wang, P.; Kong, F.D.; Gai, C.J.; Song, X.Q.; Dai, H.F. 2-(2-Phenylethyl)chromone derivatives in artificial agarwood from Aquilaria sinensis. Fitoterapia 2016, 110, 38-43. [CrossRef]

17. Wang, S.L.; Liao, H.R.; Cheng, M.J.; Shu, C.W.; Chen, C.L.; Chung, M.I.; Chen, J.J. Four New 2-(2-Phenylethyl)-4H-chromen-4-one Derivatives from the Resinous Wood of Aquilaria sinensis and Their Inhibitory Activities on Neutrophil Pro-Inflammatory Responses. Planta Med. 2018, 84, 1340-1347. [CrossRef]

18. Chinese Pharmacopoeia Commission. Chinese Pharmacopoeia; China Medical Science and Technology Press: Beijing, China, 2015.

19. Yang, B.; Wang, J.; Zhao, M.; Liu, Y.; Wang, W.; Jiang, Y. Identification of polysaccharides from pericarp tissues of litchi (Litchi chinensis Sonn.) fruit in relation to their antioxidant activities. Carbohydr. Res. 2006, 341, 634-638. [CrossRef] [PubMed]

20. Li, C.; Pan, L.; Han, Z.; Xie, Y.; Hu, H.; Liu, X.; Wu, L.; Yang, L.; Wang, Z. Antioxidative 2-(2-phenylethyl)chromones in Chinese eaglewood from Aquilaria sinensis. J. Asian Nat. Prod. Res. 2020, 22, 639-646. [CrossRef] [PubMed]

21. Berker, K.I.; Demirata, B.; Apak, R. Determination of Total Antioxidant Capacity of Lipophilic and Hydrophilic Antioxidants In the Same Solution by Using Ferric-Ferricyanide Assay. Food Anal. Methods 2012, 5, 1150-1158. [CrossRef]

22. Wang, H.N.; Dong, W.H.; Huang, S.Z.; Li, W.; Kong, F.D.; Wang, H.; Wang, J.; Mei, W.L.; Dai, H.F. Three new sesquiterpenoids from agarwood of Aquilaria crassna. Fitoterapia 2016, 114, 7-11. [CrossRef]

23. Ting, L.I.; Zhang, X.D.; Song, Y.W. A microplate-based screening method for alpha-glucosidase inhibitors. Chin. J. Clin. Pharmacol. Ther. 2005, 10, 1128-1134.

24. Poljšak, B.; Dahmane, R. Free Radicals and Extrinsic Skin Aging. Dermatol. Res. Pract. 2012, 2012, 135206. [CrossRef] [PubMed]

25. Wang, M.; Li, W.; Luo, S.; Zhao, X.; Ma, C.; Liu, S. GC-MS Study of the Chemical Components of Different Aquilaria sinensis (Lour.) Gilgorgans and Agarwood from Different Asian Countries. Molecules 2018, 23, 2168. [CrossRef]

26. Amini, M.; Zayeri, F.; Moghaddam, S.S. Years Lived with Disability due to Alzheimer's Disease and Other Dementias in Asian and North African Countries: A Trend Analysis. J. Epidemiol. Glob. Health 2019, 9, 29-35. [CrossRef] [PubMed]

27. Celik, I.E.; Acar, B.; Cay, S. An unusual cardiovascular adverse effect of donepezil. Intern. Med. J. 2015, 45, 877-878. [CrossRef]

28. Neely, G.A.; Sabir, S.; Kohli, A.; Neostigmine. StatPearls. 2020. Available online: https://www.ncbi.nlm.nih.gov/books/NBK470 596/?report=printable (accessed on 5 March 2021).

29. Hernandez-Fernandez, F.; Pardal-Fernandez, J.M.; Garcia-Martinez, E.; Segura, T. Respiratory myoclonus, a side effect of galantamine. Farm. Hosp. 2011, 35, 97-99. [CrossRef]

30. Liao, G.; Mei, W.; Kong, F.; Li, W.; Yuan, J.; Dai, H. 5,6,7,8-Tetrahydro-2-(2-phenylethyl)chromones from artificial agarwood of Aquilaria sinensis and their inhibitory activity against acetylcholinesterase. Phytochemistry 2017, 139, 98-108. [CrossRef]

31. Papatheodorou, K.; Banach, M.; Bekiari, E.; Rizzo, M.; Edmonds, M. Complications of Diabetes 2017. J. Diabetes Res. 2018, 2018, 1-4. [CrossRef]

32. Ma, Y.; Zhao, D.; Zhou, A.; Zhang, Y.; Du, Z.; Zhang, K. $\alpha$-Glucosidase Inhibition and Antihyperglycemic Activity of Phenolics from the Flowers of Edgeworthia gardneri. J. Agric. Food Chem. 2015, 63, 8162-8169. [CrossRef]

33. Sukito, A.; Darmawan, S.; Turjaman, M. Anti-oxidant and anti-diabetes activities of agarwood extracts from Gyrinops versteegii (Gilg.) Domke and their cytotoxicity. IOP Conf. Ser. Earth Environ. Sci. 2020, 415, 012001. [CrossRef]

34. Yang, L.; Yang, Y.L.; Dong, W.H.; Li, W.; Wang, P.; Cao, X.; Yuan, J.Z.; Chen, H.Q.; Mei, W.L.; Dai, H.F. Sesquiterpenoids and 2-(2-phenylethyl)chromones respectively acting as $\alpha$-glucosidase and tyrosinase inhibitors from agarwood of an Aquilaria plant. J. Enzyme Inhib. Med. Chem. 2019, 34, 853-862. [CrossRef] [PubMed]

35. Mi, C.; Yuan, J.; Zhu, M.; Yang, L.; Wei, Y.; Wang, H.; Long, W.; Mei, W.; Dai, H. 2-(2-Phenylethyl)chromone derivatives: Promising $\alpha$-glucosidase inhibitors in agarwood from Aquilaria filaria. Phytochemistry 2021, 181, 112578. [CrossRef] [PubMed] 